\title{
miR-186 promotes tumor growth in cutaneous squamous cell carcinoma by inhibiting apoptotic protease activating factor-1
}

\author{
JING TIAN ${ }^{1}$, RUI SHEN ${ }^{2}$, YUZHANG YAN ${ }^{3}$ and LIEHUA DENG ${ }^{1}$ \\ ${ }^{1}$ Department of Dermatology, The First Affiliated Hospital of Jinan University, Guangzhou, Guangdong 510632; \\ ${ }^{2}$ Department of Plastic Cosmetic Surgery, The First People's Hospital of Foshan, Foshan, Guangdong 528000; \\ ${ }^{3}$ Department of Psychiatry, Tianhe District Chronic Disease Prophylactic-Therapeutic Institution, \\ Guangzhou, Guangdong 510599, P.R. China
}

Received December 23, 2017; Accepted May 25, 2018

DOI: 10.3892/etm.2018.6679

\begin{abstract}
Cutaneous squamous cell carcinoma (cSCC) accounts for $20 \%$ of non-melanoma skin cancer worldwide. MicroRNAs (miRNAs or miRs) are a subtype of non-coding RNA associated with the progression of various types of human cancer. MiR-186 has been demonstrated to act as an oncogene in human tumors. However, the role of miR-186 in cSCC remains unclear. The expression of miR-186 and apoptotic protease activating factor 1 (APAF1) was examined using reverse transcription-quantitative polymerase chain reaction, western blotting and immunofluorescence. The correlation between miR-186 and APAF1 was determined using a dual-luciferase assay. Mimics or inhibitors of miR-186 were transfected into A-431 cells to establish cell lines with overexpressed or knocked-down miR-186, respectively. EdU staining and colony formation assays were performed to detect cell proliferation. Transwell and wound-healing assays were performed to analyze cell invasion and migration, respectively. Hoechst staining and flow cytometry were performed to assess cell apoptosis and cell cycle distribution. MiR-186 expression was significantly increased, while APAF1 expression was significantly decreased in cSCC tissues compared with the controls. An miR-186 binding site was predicted in APAF1 and their expression was negatively correlated in cSCC tissues. Cell proliferation, invasion and migration were significantly enhanced in the miR-186-overexpressed A-431 cells and attenuated in miR-186 knockdown cells compared with the control. APAF1 expression was regulated by miR-186, while APAF1 knockdown significantly promoted cell invasion and inhibited cell apoptosis. In summary, the results of the present
\end{abstract}

Correspondence to: Dr Liehua Deng, Department of Dermatology, The First Affiliated Hospital of Jinan University, 163 West Huangpu Road, Tianhe, Guangzhou, Guangdong 510632, P.R. China E-mail: denglh_soso@163.com

Key words: cutaneous squamous cell carcinoma, microRNA-186, apoptotic protease activating factor 1, proliferation, apoptosis, invasion, migration study indicate that miR-186 serves as an oncogene in cSCC by inhibiting APAF1.

\section{Introduction}

The worldwide incidence of skin cancer has increased rapidly with 2.75 million new cases in the worldwide annually (1). This is due to damage to the ozonosphere and a lack of risk awareness $(1,2)$. Non-melanoma skin cancer (NMSC) is one of the most common types of skin cancer and has a number of subtypes, including basal cell carcinoma, cutaneous squamous cell carcinoma (cSCC), merkel cell carcinoma and microcystic adnexal carcinoma (3-5). cSCC is the most frequent cutaneous carcinoma, following basal cell carcinomas and accounts for $>20 \%$ of all skin cancer cases all over the world (5-7). The initiation and development of cSCC is caused by complex interactions between various signaling molecules associated with genetics, infection, chemistry and immunity (8). Tumor recurrence and metastasis are thought to be the leading causes of mortality for patients with $\operatorname{cSCC}(9,10)$. A previous study demonstrated that patients with cSCC recurrence and metastasis have a poor long-term prognosis, with a one-year survival rate of $\sim 50 \%$ (11). Therefore, developing effective, novel, molecular targets for the detection and treatment of $\mathrm{cSCC}$ is of great importance.

MicroRNAs (miRNAs or miRs) are small non-coding RNAs (2-24 nucleotides in length) that regulate gene expression by interacting with target genes at a post-transcriptional level $(12,13)$. miRNA-186 (miR-186) is an important member of the miRNA family and accumulating evidence has revealed that miR-186 may serve a critical role in various biological processes, including cell development, proliferation and apoptosis (14-16). Previous evidence also indicates that miR-186 may serve a role in various types of human cancer, including bladder, pancreatic and liver cancer (17-19). However, whether miR-186 is associated with the pathogenesis of cSCC remains undetermined.

Apoptotic protease activating factor 1 (APAF1) is a critical component of the apoptosome and previous studies have demonstrated that it may be activated by various cellular stimuli, including DNA damage and oncogene activation $(20,21)$. APAF1 inactivation is a common event in 
human tumors, which suggests that it may serve as a tumor suppressor in healthy individuals (22). Recently, APAF1 was identified as a target gene of miR-23a and miR-221 in colorectal and ovarian cancer, respectively $(23,24)$. However, whether APAF1 serves a role in the pathogenesis of cSCC remains unclear.

In the present study, the expression of miR-186 and APAF1 was examined in cSCC cells and tissues. The correlation between miR-186 and APAF1 was subsequently investigated using bioinformatics analysis and a dual-luciferase activity assay. A-431 cell lines with knocked down miR-186, overexpressed miR-186, knocked down APAF1 or overexpressed miR-186 and knocked down APAF1 were established to explore the role of miR-186 and APAF1 in cSCC.

\section{Materials and methods}

Cell lines and tissues. The human cSCC cell line A-431 and the 293-T cell line were purchased from the American Type Culture Collection (Manassas, VA, USA) and cultured in Dulbecco's modified Eagle's medium (DMEM; Invitrogen; Thermo Fisher Scientific, Inc., Waltham, MA, USA) supplemented with $10 \%$ fetal bovine serum (FBS; Gibco; Thermo Fisher Scientific, Inc.) and $1 \%$ penicillin/streptomycin (Sigma-Aldrich; Merck KGaA, Darmstadt, Germany). The cells were maintained in a humidified incubator with $5 \% \mathrm{CO}_{2}$ at $37^{\circ} \mathrm{C}$.

A total of 15 paired tumor and adjacent normal tissues (5 cm away from each tumor) were obtained at the same locations from patients diagnosed with cSCC during surgery between August 2015 and March 2017 at the First Affiliated Hospital of Jinan University (Guangzhou, China). These cSCC cases included 8 male patients and 7 female patients with a mean age of 62.7 years (range, 38-87 years). All tissue samples were collected, immersed in liquid nitrogen and maintained at $-80^{\circ} \mathrm{C}$ for further experiments. Written informed consent was obtained from each patient prior to the current study. The study protocol was approved by the Research Ethics Committee at the First Affiliated Hospital of Jinan University (Guangzhou, China).

Overexpression andknockdownexperiments.For the overexpression and knockdown experiments of miR-186, mimic (3'-CAA AGAAUUCUCCUUUUGGGCU-5'), inhibitor (3'-AGCCCA AAAGGAGAAGGCUUUG-5') and negative control (NC; 3'-UUCUCCGAACGUGUCACGUTT-5') sequences were designed by Shanghai GenePharma Co., Ltd. (Shanghai, China). A-431 cells were transfected with the miRNA NC, miR-186 mimic or miR-186 inhibitor (all $100 \mathrm{nM}$ ) using Lipofectamine ${ }^{\circledR}$ 2000 (Invitrogen; Thermo Fisher Scientific, Inc.) according the manufacturer's protocol for $24 \mathrm{~h}$.

For APAF1 knockdown, APAF1 siRNA (si-APAF1; 3'-GUGCCUACAAAGGUGUUAUUU-5') and NC siRNA for APAF1 (NC-siRNA; 3'-UUCUCCGAACGUGUCACG UUU-5') were designed by Shanghai GenePharma Co., Ltd. The A-431 cells were transfected with si-APAF1 or NC-siRNA (both $25 \mathrm{nM}$ ) with or without miR-186 inhibitor (100 nM) using Lipofectamine 2000 according to the manufacturer's protocol for $24 \mathrm{~h}$.
RNA extraction and reverse transcription-quantitative polymerase chain reaction $(R T-q P C R)$. Total RNA was extracted from cSCC and control tissues, and miR-NC-, miR-186 mimicor miR-186 inhibitor-transfected A-431 cells using TRIzol reagent (Invitrogen; Thermo Fisher Scientific, Inc.). mRNA was reverse transcribed into cDNA using the Revert Aid First Strand cDNA Synthesis kit (cat. no. K1622; Thermo Fisher Scientific, Inc.) according to the manufacturer's protocol, and the thermocycling conditions were $25^{\circ} \mathrm{C}$ for $5 \mathrm{~min}, 42^{\circ} \mathrm{C}$ for $60 \mathrm{~min}$ and $70^{\circ} \mathrm{C}$ for $10 \mathrm{~min}$. qPCR was performed using SYBR-Green Real-Time Master mix (Toyobo Life Science, Osaka, Japan) following the manufacturer's protocol. The thermocycling conditions of qPCR were as follows: $95^{\circ} \mathrm{C}$ for $10 \mathrm{~min}$, followed by 40 cycles of $95^{\circ} \mathrm{C}$ for $15 \mathrm{sec}$ and $60^{\circ} \mathrm{C}$ for $1 \mathrm{~min}$. GAPDH and U6 were used as internal controls for APAF1 and miR-186, respectively. The primers used for the detection of miR-186 and APAF1 were as follows: miR-186, sense 5'-GCGGCGCAAAGAATTCTCCT-3' and antisense 5'-GTGCAGGGTCCGAGGT-3'; APAF1, sense 5'-ATGGAC ACCTTCTTGGACGACAG-3' and antisense 5'-TGTGGG GGCGGACAACTAA-3'; GAPDH, sense 5'-TGTTCGTCA TGGGTGTGAAC-3' and antisense 5'-ATGGCATGGACT GTGGTCAT-3'; U6, sense 5'-CGCTTCGGCAGCACATAT ACTA-3' and antisense 5'-CGCTTCACGAATTTGCGT GTCA-3'. Primers were designed by Sangon Biotech Co., Ltd. (Shanghai, China). The relative expression of miR-186 and APAF1 were calculated and normalized using the $2^{-\Delta \Delta C q}$ method (25).

Western blot analysis. Total protein was extracted from the tissue samples and miR-NC-, miR-186 mimic-, miR-186 inhibitor, si-APAF1+miR-186 inhibitor or NC-siRNA+miR-186 inhibitor-transfected A-431 cells using an SDS lysis buffer (cat. no. P0013G; Beyotime Institute of Biotechnology, Haimen, China) on ice for $30 \mathrm{~min}$. The concentration of total protein was measured using a bicinchoninic acid protein assay kit (Pierce; Thermo Fisher Scientific, Inc.). A total of $50 \mu \mathrm{g} /$ lane protein was separated by $10 \%$ SDS-PAGE and transferred onto polyvinylidene difluoride membranes (EMD Millipore, Billerica, MA, USA). Membranes were blocked with $10 \%$ low fat dried milk at $25^{\circ} \mathrm{C}$ for a minimum of $1 \mathrm{~h}$, followed by incubation with primary antibodies against APAF1 (1:1,000; cat. no. ab32372), light chain 3B (LC3-B; 1:500; cat. no. ab48394) or Beclin1 (1:1,000; cat. no. ab62557; all Abcam, Cambridge, MA, USA) for $1 \mathrm{~h}$ at room temperature (RT). Membranes were subsequently incubated with horseradish peroxidase-conjugated secondary antibodies (cat. no. BA1054; Wuhan Boster Biological Technology, Ltd., Wuhan, China) for $2 \mathrm{~h}$ at RT. GAPDH was used as the internal control and signals were detected using enhanced chemiluminescent reagents (cat. no. SW2030; Beijing Solarbio Science \& Technology Co., Ltd., Beijing, China). The band net optical density was analysed using Image-Pro Plus software (version 6.0; Media Cybernetics, Inc., Rockville, MD, USA).

Luciferase reporter transfection and dual-luciferase reporter assay. The TargetScan database (targetscan.org) predicted one binding site for miR-186 on APAF1. A wild-type (WT) APAF1 [WT-3'-untranslated region (UTR)-APAF1] with the predicted miR-186 target binding sequence and a mutant 
APAF1 (MUT-3'-UTR-APAF1) with a mutation in the binding site, were synthesized and cloned into the psi-CHECK2 vector (cat. no. C8021; Promega Corporation, Madison, WI, USA). The 293-T cells were seeded in 96-well plates at a density of $1 \times 10^{4}$ cells/well. Following overnight incubation at $37^{\circ} \mathrm{C}$, the 293-T cells were transfected with the reconstructed plasmid containing WT-3'-UTR-APAF1 or MUT-3'-UTR-APAF1 in the presence of miR-186 mimics or the negative control (NC) by Lipofectamine ${ }^{\circledR} 2000$. Cells were harvested and the luciferase activity was measured using a Dual-Luciferase Reporter assay system (Promega Corporation, Madison, WI, USA) $48 \mathrm{~h}$ following transfection. Renilla luciferase activity was used for normalization of the firefly luciferase activity.

Immunofluorescence. miR-NC-, miR-186 mimic- or miR-186 inhibitor-transfected A-431 cells were seeded at a density of $1 \times 10^{5}$ cells $/ \mathrm{ml}$ on a coverslip pre-coated with poly-L-lysine. They were subsequently fixed with cold $4 \%$ formaldehyde at $4^{\circ} \mathrm{C}$ overnight. After washing three times with PBS containing $0.1 \%$ Triton X-100, cells were blocked with $10 \%$ bovine serum albumin (cat. no. FA016-50G; Amresco, LLC, Solon, $\mathrm{OH}, \mathrm{USA}$ ) for $2 \mathrm{~h}$ at RT followed by incubation with primary antibodies against APAF1 (1:1,000; cat. no. ab2001; Abcam) and DAPI (1:2,000; cat. no. ab104139; Abcam) at $4^{\circ} \mathrm{C}$ overnight. Cells were then incubated with Alexa Fluor 488 donkey anti-mouse immunoglobulin G (1:200; ab150105; Abcam) secondary antibodies for $1 \mathrm{~h}$ at RT and visualized using a confocal laser-scanning microscope. Magnification at x200.

Hoechst staining. si-APAF1+miR-186 inhibitor or NC-siRNA+miR-186 inhibitor-transfected A-431 cells were seeded into 6-well plates and incubated overnight at $37^{\circ} \mathrm{C}$. Cells were fixed with $50 \mu 1$ cold $4 \%$ formaldehyde for $30 \mathrm{~min}$ at RT. Then the cells were washed twice with cold PBS. Hoechst 33258 was added to the wells at a concentration of $20 \mu \mathrm{g} / \mathrm{ml}$ (Sigma-Aldrich; Merck KGaA) and incubated for a minimum of $20 \mathrm{~min}$ at RT. Following washing with PBS, the cells were visualized using a Leica confocal laser-scanning microscope (TCS SP8; Leica Microsystems GmbH, Wetzlar, Germany) at $365 \mathrm{~nm}$. Magnification at x400.

EdU staining. The Click-iT Plus EdU Alexa Fluor 1594 Imaging kit (Invitrogen; Thermo Fisher Scientific, Inc.) was used according to the manufacturer's protocol, to determine the effects of miR-186 mimics or inhibitor on cell proliferation. miR-NC-, miR-186 mimic- or miR-186 inhibitor-transfected A-431 cells were fixed with $50 \mu 1$ cold $4 \%$ formaldehyde for 30 min at RT. DAPI $(1: 2,000)$ was used to stain the cell nucleus for $30 \mathrm{~min}$ at RT and signals were detected using an Olympus FLUOVIEW FV1000 confocal laser-scanning microscope (Olympus Corporation, Tokyo, Japan) at a magnification of $\mathrm{x} 100$.

Colony formation assay. A-431 cells transfected with miR-186 $\mathrm{NC}$, mimic or inhibitor were seeded onto glass dishes at a density of $1 \times 10^{3}$ cells $/ \mathrm{ml}$ and incubated in an atmosphere containing $5 \% \mathrm{CO}_{2}$ at $37^{\circ} \mathrm{C}$ for 2 weeks. The cells were fixed with $50 \mu \mathrm{l}$ cold $4 \%$ formaldehyde for $30 \mathrm{~min}$ at RT and subsequently stained with $0.1 \%$ crystal violet for $15 \mathrm{~min}$ at RT. Local cloning morphology was photographed with an inverted microscope. The colonies were counted and each of the experimental conditions was performed by using a Nikon Eclipse Ti inverted microscope (Nikon Corporation, Tokyo, Japan) in triplicate. Magnification at x100.

Matrigel invasion assay. To evaluate the effects of miR-186 on the invasive ability of cSCC cells, a Matrigel assay was performed. miR-NC-, miR-186 mimic-, miR-186 inhibitor, si-APAF1+miR-186 inhibitor or NC-siRNA+miR-186 inhibitor-transfected A-431 cells were suspended in $100 \mu \mathrm{l}$ DMEM at a concentration of $1 \times 10^{5}$ cells $/ \mathrm{ml}$ and seeded into the upper Transwell chamber with an $8-\mu \mathrm{m}$ pore size coated with Matrigel (Corning Inc., Corning, NY, USA). A total of $200 \mu$ l DMEM containing 15\% FBS was added to the lower Transwell chamber and cells were cultured at $37^{\circ} \mathrm{C}$ for $24 \mathrm{~h}$. Cells in the upper chamber were removed and those in the lower chamber were fixed with $4 \%$ paraformaldehyde for 30 min at RT stained with $0.1 \%$ crystal violet for $5 \mathrm{~min}$ at RT and observed using a Nikon Eclipse Ti inverted microscope in triplicate Magnification at x200.

Wound-healing assay. A wound-healing assay was used to assess the effects of miR-186 on cell migration ability. miR-NC-, miR-186 mimic- or miR-186 inhibitor-transfected A-431 cells were seeded in 6-well plates at a concentration of $1 \times 10^{4}$ cells/well. A parallel wound was made using a pipette tip once the A- 431 cells reached $100 \%$ confluence. Cells were then cultured at $37^{\circ} \mathrm{C}$ in a $5 \% \mathrm{CO}_{2}$ atmosphere and images were captured using an inverted microscope at 0 and $48 \mathrm{~h}$. Magnification at x100.

Cell apoptosis and cell cycle distribution analyses. To assess cell apoptosis and perform cell cycle analysis, miR-NC-, miR-186 mimic- or miR-186 inhibitor-transfected A-431 cells were seeded in 24-well plates at a density of $1 \times 10^{5}$ cells/well and cultured in DMEM with $10 \%$ FBS at $37^{\circ} \mathrm{C}$ for $24 \mathrm{~h}$. For the cell cycle distribution analysis, the cells were digested by trypsin (Gibco; Thermo Fisher Scientific, Inc.), washed with PBS three times and fixed with $80 \%$ ethanol for $5 \mathrm{~min}$ at $4{ }^{\circ} \mathrm{C}$. They were then incubated with $0.25 \mathrm{mg} / \mathrm{ml}$ Ribonuclease A (Sigma-Aldrich; Merck KGaA) for $30 \mathrm{~min}$ at $37^{\circ} \mathrm{C}$ and $20 \mu \mathrm{g} / \mathrm{ml}$ propidium iodide (Nanjing KeyGen Biotech Co., Ltd., Nanjing, China) for $20 \mathrm{~min}$ at room temperature. For the cell apoptosis analysis, the cells were digested with trypsin, centrifuged at $111.8 \mathrm{x}$ g for $5 \mathrm{~min}$ at $4^{\circ} \mathrm{C}$, washed with PBS, re-suspended in $100 \mu 11 \mathrm{X}$ binding buffer [cat. no. 70-AP101-100-BB; Hangzhou Multi Sciences (Lianke) Biotech Co., Ltd., Hangzhou, China]. Then the cells were double stained with an Annexin V-FITC/PI apoptosis detection kit (Bestbio Company, Shanghai China) in the dark for $15 \mathrm{~min}$ at room temperature. Following staining, the apoptosis rate and cell cycle distribution was analyzed using a BD Accuri ${ }^{\mathrm{TM}}$ C6 Plus flow cytometer and equipped with CellQuest software (version 6.1x; both BD Bioscience, San Jose, CA, USA) according to the manufacturer's protocol.

Statistical analysis. Data are presented as the mean \pm standard deviation and all statistical analyses were performed using SPSS 20.0 software (IBM Corp., Armonk, NY, USA). Cell experiments had $>3$ biological replicates. One-way analysis of variance and the least significant difference post hoc multiple 

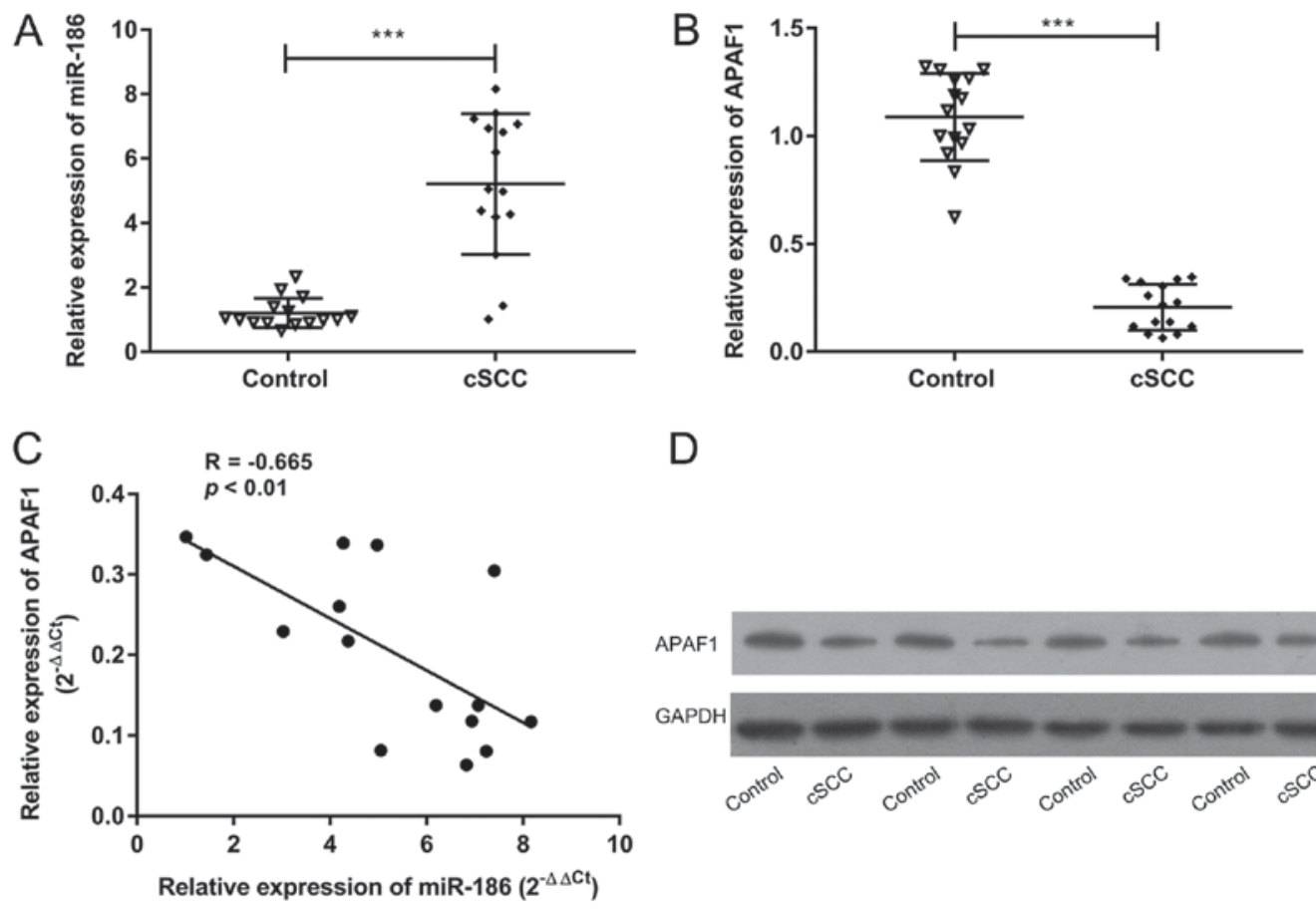

D

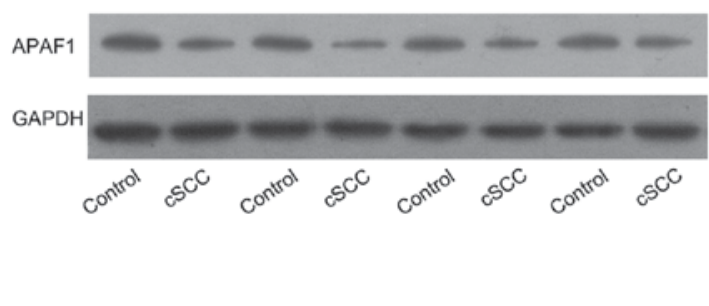

Figure 1. miR-186 and APAF1 expression and their correlation in cSCC tissues. Reverse transcription-quantitative polymerase chain reaction was used to detect the expression of (A) miR-186 and (B) APAF1 in cSCC tissues and their corresponding controls. (C) Correlation between miR-186 expression and APAF1 expression. (D) Western blotting was performed to detect the protein expression of APAF1 in cSCC tissues and corresponding controls. ${ }^{* * *} \mathrm{P}<0.001$. miR, microRNA; cSCC, cutaneous squamous cell carcinoma; APAF1, apoptotic protease activating factor 1.

comparison test were used to compare the differences among multiple groups. $\mathrm{P}<0.05$ was considered to indicate a statistically significant difference.

\section{Results}

miR-186 expression is upregulated and APAF1 expression is downregulated in cSCC tissues. To investigate the precise roles of miR-186 and APAF1 in the tumorigenesis of CSCC, their expression in cSCC tissues was compared with corresponding normal tissues. RT-qPCR results revealed that miR-186 expression was significantly higher in cSCC tissues compared with the corresponding normal tissues $(\mathrm{P}<0.001$, Fig. 1A). Conversely, APAF1 expression was significantly reduced in cSCC tissues compared with the control samples $(\mathrm{P}<0.001$, Fig. 1B). In addition, the relative expression of APAF1 was negatively correlated with the expression of miR-186 in cSCC tissues $(\mathrm{R}=-0.665, \mathrm{P}<0.01$; Fig. $1 \mathrm{C})$. Western blotting revealed that the expression of APAF1 protein was reduced in $\mathrm{CSCC}$ tissues compared with the controls (Fig. 1D). These results suggest that miR-186 and APAF1 may serve a critical role in the pathogenesis of $\mathrm{CSCC}$.

APAF1 is a potential target gene of miR-186. To further explore the correlation between APAF1 and miR-186, the TargetScan miRNA target predication database was used. One predictive target site for miR-186 was identified in APAF1 (Fig. 2A). A dual-luciferase reporter assay revealed that the relative luciferase activity was significantly attenuated by miR-186 mimics in the WT-3'-UTR-APAF1 system, whereas it was not significantly altered by the application of miR-186 mimics in the MUT-3'-UTR-APAF1 system
A hsa-miR-186 3' UCGGGUUUUCCUCUUAAGAAAC APAF1 5 '... AUUGUGCAAUGCCAAUUCUUUU $\cdots 3^{\prime}$

B

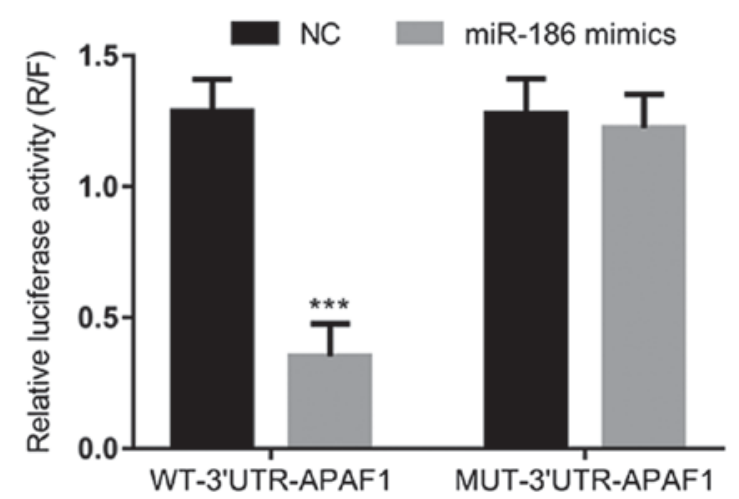

Figure 2. Interaction between miR-186 and APAF1. (A) TargetScan was used to reveal the sequence alignment of miR-186 and APAF1 mRNA. (B) A dual-luciferase reporter assay was performed to determine whether APAF1 was a target gene of miR-186. ${ }^{* * *} \mathrm{P}<0.001$ vs. the $\mathrm{NC}$ group. $\mathrm{NC}$, negative control; miR, microRNA; APAF1, apoptotic protease activating factor 1 ; WT, wild-type; MUT, mutant; UTR, untranslated region.

(P<0.001; Fig. 2B). These results suggest that the APAF1 gene is a direct target of miR-186.

APAF1 expression is regulated by miR-186. To determine how miR-186 regulates the expression of APAF1, RT-qPCR, immunohistochemistry and western blotting were performed 

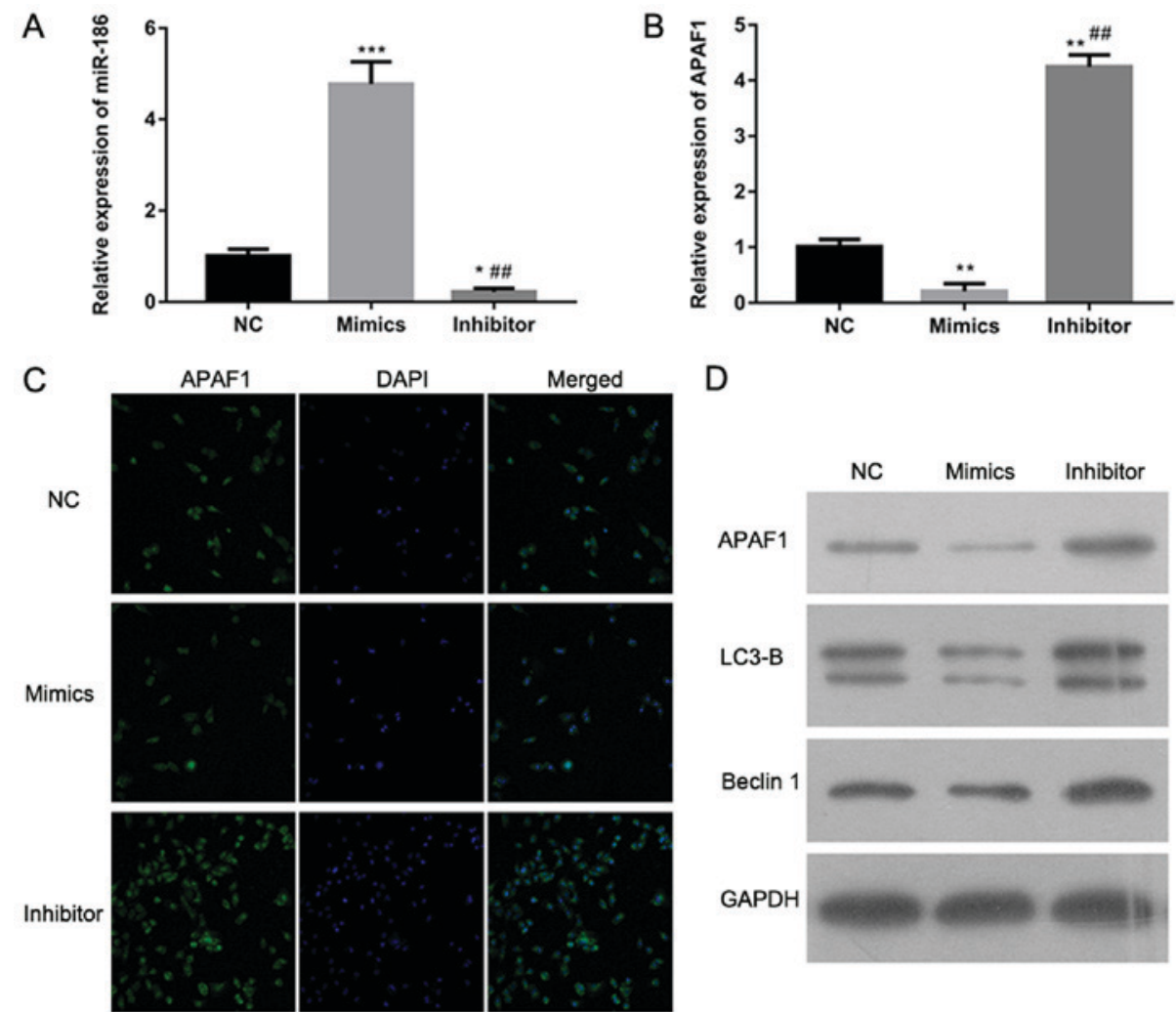

Figure 3. Effect of miR-186 overexpression or knockdown on APAF1 expression in A-431 cells. The expression of (A) miR-186 and (B) APAF1 was examined using reverse transcription-quantitative polymerase chain reaction in A-431 cells transfected with miR-186 mimics or inhibitor. ${ }^{*}<0.05$, ${ }^{* *} \mathrm{P}<0.01$ and ${ }^{* * * *} \mathrm{P}<0.001$ vs. the $\mathrm{NC}$ group; ${ }^{* \#} \mathrm{P}<0.01$ vs. the mimics group. (C) Immunofluorescence analysis was performed to investigate the expression of APAF1 in A-431 cells transfected with miR-186 mimics or inhibitors. Magnification, x200. (D) Western blotting was performed to examine the expression of APAF1, LC3-B and Beclin1 protein in miR-186 overexpression or knockdown A-431 cells. GAPDH was used as the internal control. NC, negative control; miR, microRNA; APAF1, apoptotic protease activating factor 1; LC3-B, light chain 3B.

to detect APAF1 expression in A-431 cells with miR-186 overexpression or knockdown. The RT-qPCR results revealed that miR-186 expression was significantly increased in A-431 cells transfected with miR-186 mimics and significantly decreased in A-431 cells transfected with miR-186 inhibitors compared with the $\mathrm{NC}$ group $(\mathrm{P}<0.001$ and $\mathrm{P}<0.05$, respectively; Fig. 3A). The RT-qPCR assay also demonstrated that APAF1 expression was significantly downregulated in A-431 cells transfected with miR-186 mimics and significantly upregulated in those transfected with miR-186 inhibitors ( $\mathrm{P}<0.01$; Fig. 3B). Immunohistochemistry and western blotting also supported these results (Fig. 3C and D). Western blotting indicated that the expression of LC3-B and Beclin1 was lower in A-431 cells transfected with miR-186 mimics and markedly higher in A-431 cells transfected with miR-186 inhibitors compared with the NC group (Fig. 3D). These results indicate that APAF1 expression is directly regulated by miR-186 in the A-431 cSCC cell line.

miR-186 promotes cell proliferation, invasion and migration and inhibits cell apoptosis in the A-431 cell line. To understand the role of miR-186 in the tumorigenesis of $\mathrm{cSCC}$, proliferation, invasion, migration and apoptosis were investigated in A-431 cells transfected with miR-186 mimics or inhibitors. EdU staining and colony formation assays were used to examine the effects of miR-186 on cell proliferation. The results revealed the proliferation ability was increased in A-431 cells transfected with miR-186 mimics compared with the NC-transfected cells, while proliferation was decreased in A-431 cells transfected with miR-186 inhibitors (Fig. 4A and B). Transwell and wound-healing assays demonstrated that invasion and migration were significantly enhanced in A-431 cells transfected with miR-186 mimics and significantly attenuated in A-431 cells transfected with the miR-186 inhibitor compared with the NC-treated cells ( $\mathrm{P}<0.01$; Fig. $4 \mathrm{C}$ and D). Cell apoptosis was not significantly affected in A-431 cells transfected with miR-186 mimics compared with the NC group; however, it was significantly upregulated in A-431 cells transfected with miR-186 inhibitors $(\mathrm{P}<0.01$; Fig. $4 \mathrm{E})$. Flow cytometry was performed to assess the effects of miR-186 on cell cycle distribution. The results revealed that miR-186 overexpression significantly decreased the percentage of A-431 cells in the G0/G1 phase and significantly increased the percentage of A-431 cells in $\mathrm{S}$ phase compared with the NC group $(\mathrm{P}<0.05$ and $\mathrm{P}<0.01$, Fig. 4F). These results suggest that miR-186 may act as an oncogene in the cSCC A-431 cell line.

APAF1 knockdown promotes invasion and inhibits apoptosis in A-431 cells transfected with miR-186 inhibitors. To further explore the role of APAF1 in cSCC, miR-186 expression was assessed using RT-qPCR and the expression of APAF1, LC3-B and Beclin1 proteins was analyzed using western blotting in A-431 cells transfected with miR-186 inhibitors with or without si-APAF1. The results revealed that miR-186 expression was 
A

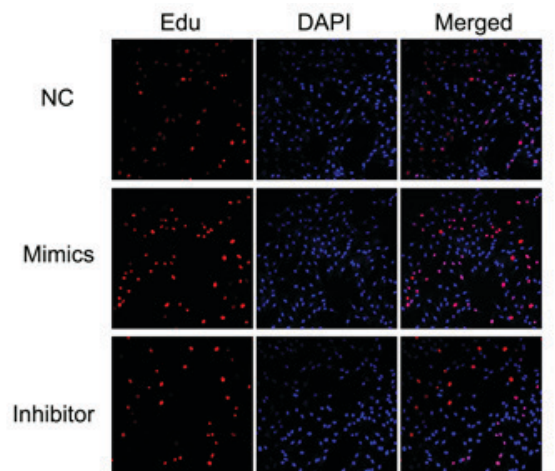

B

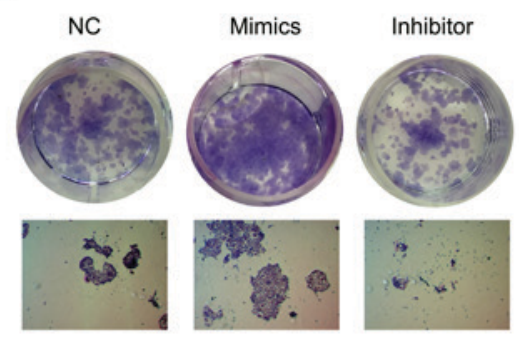

C
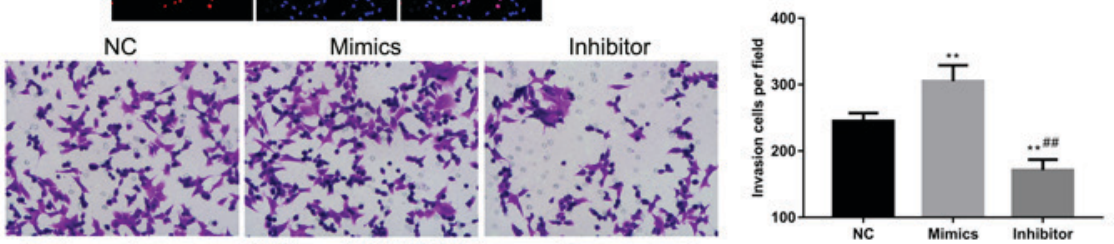

$\mathrm{D}$
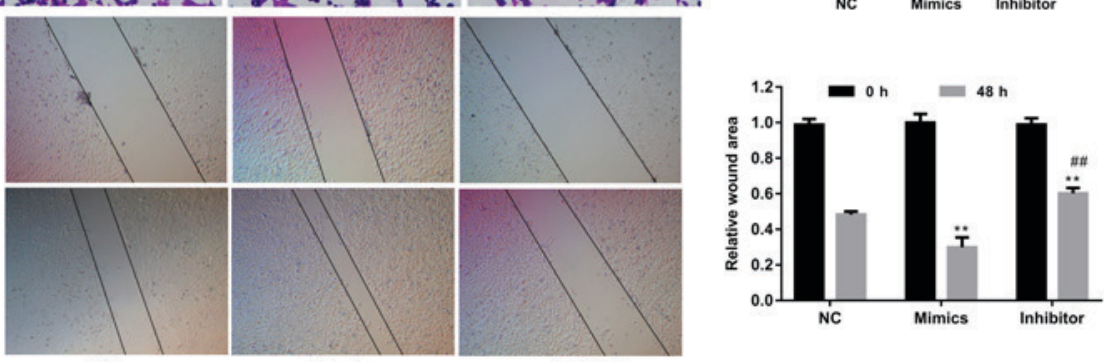

$\mathrm{E}$
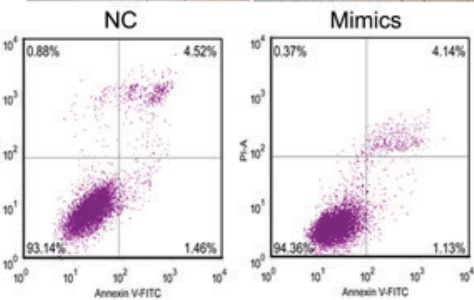

Inhibitor
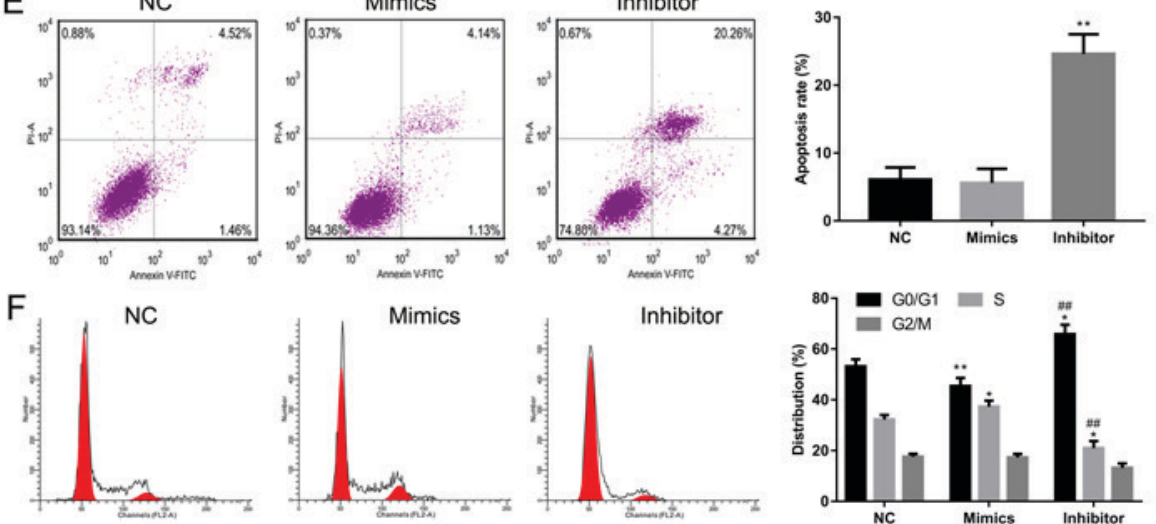

Figure 4. Effect of miR-186 overexpression or knockdown on cell proliferation, apoptosis, invasion and cell cycle progression in A-431 cells. (A) EdU staining was performed in the NC, miR-186 mimics and miR-186 inhibitors groups. Red indicates EdU staining and blue indicates DAPI. Magnification, x100. (B) A colony formation assay was performed to assess the effect of miR-186 on cell proliferation in the NC, mimics and inhibitor groups. Magnification, x100. (C) A Transwell assay was performed to detect the invasive ability of A-431 cells transfected with NC, mimics or inhibitor. Magnification, x200. (D) A wound-healing assay was used to assess the migratory ability of A-431 cells treated with NC, mimics or inhibitor. Magnification, x100. (E and F) Annexin V-FITC/PI staining and flow cytometry analysis were performed to evaluate the effects of miR-186 on (E) cell apoptosis and (F) cell cycle distribution in miR-186 overexpressed or inhibited A-431 cells, respectively. ${ }^{*} \mathrm{P}<0.05,{ }^{* *} \mathrm{P}<0.01$ vs. NC group. ${ }^{\# \#} \mathrm{P}<0.01$ vs. mimics group. NC, negative control; miR, microRNA; APAF1, apoptotic protease activating factor 1; FITC, fluorescein isothiocyanate; PI, propidium iodide.

significantly decreased in the si-APAF1 transfected group compared with the control group $(\mathrm{P}<0.01$; Fig. $5 \mathrm{~A})$. Western blotting demonstrated that APAF1, LC3-B and Beclin1 protein expression was notably decreased in A-431 cells transfected with miR-186 inhibitors and si-APAF1, compared with the A-431 cells transfected with miR-186 inhibitors alone (Fig. 5B). A Matrigel assay and Hoechst staining were performed to evaluate the effect of APAF1 on cell invasion and apoptosis in A-431 cells transfected with miR-186 inhibitors. The results suggest that cell invasion is significantly enhanced, while migration is markedly attenuated in A-431 cells transfected with miR-186 inhibitors and si-APAF1 compared with A-431 cells transfected with the miR-186 inhibitor alone $(\mathrm{P}<0.01$; Fig. 5C and D). These results suggest that APAF1 may act as a tumor suppressor in the A-431 cSCC cell line.

\section{Discussion}

Despite advances in the prevention, diagnosis and treatment of cSCC worldwide, the exact molecular basis of cSCC remains unclear $(5,26,27)$. miRNAs are considered to be important genetic regulators of various biological processes, including cell proliferation, development, invasion and apoptosis (28-30). A number of previous studies have 
A

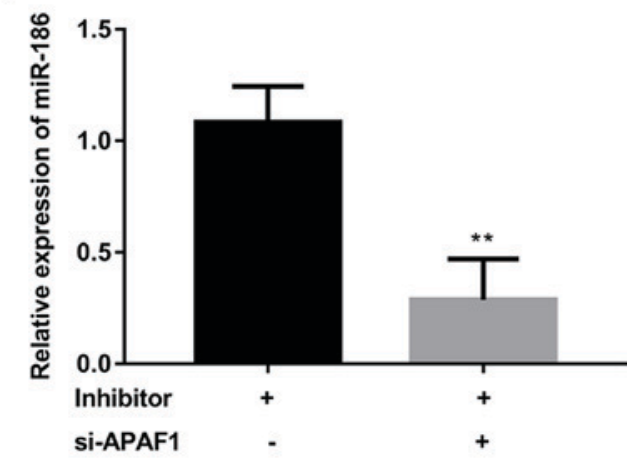

C

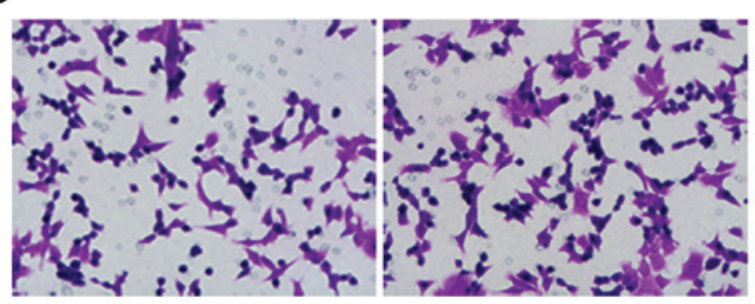

Inhibitor+NC
$B$

APAF1

LC3-B
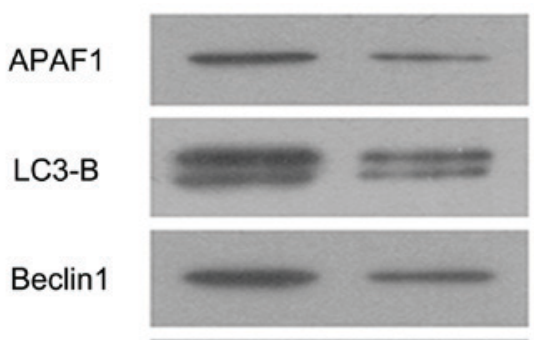

GAPDH
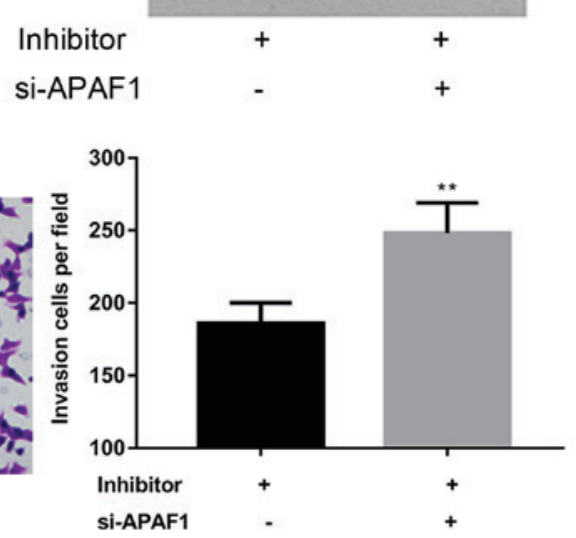

D

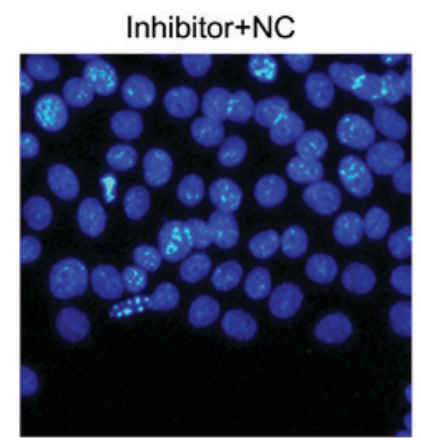

Inhibitor+si-APAF1

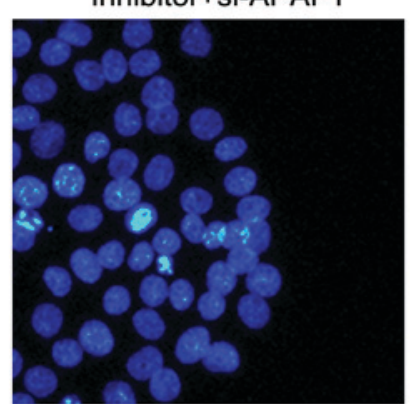

Figure 5. Effect of APAF1 knockdown on the proliferation and apoptosis of A-431 cells. (A) The expression of miR-186 was examined by reverse transcription-quantitative polymerase chain reaction in A-431 cells with or without si-APAF1 in the presence of miR-186 inhibitors. (B) Western blotting was performed to detect the expression of APAF1, LC3B and Beclin1 proteins in A-431 cells treated with miR-186 inhibitors in the presence or absence of si-APAF1. (C) The invasive ability of A-431 cells treated with miR-186 inhibitors alone or in combination with si-APAF1 was measured using a Matrigel assay. Magnification, x200. (D) Hoechst 33258 staining was performed to assess the apoptosis of A-431 cells transfected with miR-186 inhibitors with or without si-APAF1. Magnification, $\mathrm{x} 400 .{ }^{* *} \mathrm{P}<0.01$ vs. Inhibitor+NC. APAF1, apoptotic protease activating factor 1; LC3-B, light chain 3B; miR, microRNA; si, short interfering; $\mathrm{NC}$, negative control.

demonstrated that miRNAs are involved in the pathogenesis of a number of human diseases, particularly different types of cancer $(12,31,32)$. Aberrant miRNA expression is frequently observed in cancer, including pancreatic, breast and various types of skin cancer (33-35). Increasing numbers of miRNAs have been identified as critical regulators in the initiation and progression of cSCC, including miR-1, miR-34a, miR-124 and miR-125b (36-39). Fleming et al (36) reported that miR-1 expression was reduced in cSCC cell lines, while the results of functional assays indicated that miR-1 inhibits cell proliferation and promotes cell apoptosis by targeting various genes. It has been reported that miR-125 is a tumor suppressor in cSCC, while matrix metallopeptidase 13 was identified as its gene target (39). It was demonstrated that miR-186 was associated with a number of different types of human cancer, including bladder cancer, hepatocellular carcinoma and gastric cancer; however, its involvement in the tumorigenesis of cSCC remains unclear $(17,40,41)$. The present study revealed that miR-186 expression was upregulated and cell proliferation, invasion and migration were promoted in A-431 cells, suggesting that miR-186 is an oncogene in cSCC.

APAF1 serves a critical role as a regulator of the mitochondrial apoptotic signaling pathway, inducing cell apoptosis by binding with cytochrome $\mathrm{C}$ and activating caspase- 9 in the cytosol (21). Previous studies have demonstrated that APAF1 functions as a tumor suppressor by interacting with various miRNAs (40-42). Li et al (24) reported that miR-221 expression was significantly increased in ovarian tumor tissues and that it promoted cell proliferation by inhibiting APAF1 expression. Zang et al (43) observed that miR-155 expression was significantly increased and APAF1 expression was notably reduced in lung cancer tissues. They also reported that miR-155 attenuated the sensitivity of lung cancer cell 
lines to cisplatin by decreasing APAF1 expression. In the present study, a negative correlation between miR-186 and APAF1 was observed in cSCC tissues. It was revealed that APAF1 is a direct target gene of miR-186, which suggests that APAF1 may serve as a downstream signaling molecule of miR-186. Consistent with previous studies, further functional assays have demonstrated that APAF1 knockdown in A-431 cSCC cells may enhance their invasive ability and attenuate migration $(24,43,44)$.

LC3-B and Beclin1 are considered to be critical autophagy-associated genes and their expression levels are often used to assess autophagic activity (45-47). In the present study, it was revealed that LC3-B and Beclin1 expression was significantly downregulated in A-431 cells transfected with miR-186 mimics or inhibitors co-incubated with APAF1 siRNA. This suggests that LC3-B and Beclin1 may be potential therapeutic targets for patients with $\mathrm{cSCC}$.

In conclusion, the results of the present study demonstrate that APAF1 acts as a target gene of miR-186 in A-431 cSCC cells, while miR-186 upregulation promotes cell proliferation, invasion and migration and inhibits cellular apoptosis. APAF1 knockdown promoted cell growth and inhibited cell apoptosis. These results suggest that therapeutic agents targeting the miR-186/APAF1 axis may have potential clinical applications as a treatment option for $\mathrm{CSCC}$.

\section{Acknowledgements}

Not applicable.

\section{Funding}

Not applicable.

\section{Availability of data and materials}

All data generated or analyzed during the current study are included in this published article.

\section{Authors' contributions}

JT and LHD made substantial contributions to conception and design, and analysis of data. RS and YZY helped in drafting the manuscript. JT and LHD revised the manuscript. All authors read and approved the final version.

\section{Ethics approval and consent to participate}

The study protocol was approved by the Research Ethics Committee at the First Affiliated Hospital of Jinan University and written informed consent was obtained from each participant prior to their inclusion within the study.

\section{Patient consent for publication}

Not applicable.

\section{Competing interests}

The authors declare that they have no competing interests.

\section{References}

1. Gordon R: Skin cancer: An overview of epidemiology and risk factors. Semin Oncol Nurs 29: 160-169, 2013.

2. Linares MA, Zakaria A and Nizran P: Skin cancer. Prim Care 42 : 645-659, 2015.

3. Glass AG and Hoover RN: The emerging epidemic of melanoma and squamous cell skin cancer. JAMA 262: 2097-2100, 1989.

4. Dubas LE and Ingraffea A: Nonmelanoma skin cancer. Facial Plast Surg Clin North Am 21: 43-53, 2013.

5. Parekh V and Seykora JT: Cutaneous squamous cell carcinoma. Clin Lab Med 37: 503-525, 2017.

6. Green AC and Olsen CM: Cutaneous squamous cell carcinoma: An epidemiological review. Br J Dermatol 177: 373-381, 2017.

7. Leiter U, Gutzmer R, Alter M, Ulrich C, Lonsdorf AS, Sachse MM and Hillen U: Cutaneous squamous cell carcinoma. Hautarzt 67: 857-866, 2016 (In German).

8. Prieto-Granada C and Rodriguez-Waitkus P: Cutaneous squamous cell carcinoma and related entities: Epidemiology, clinical and histological features, and basic science overview. Curr Probl Cancer 39: 206-215, 2015.

9. Thompson AK, Kelley BF, Prokop LJ, Murad MH and Baum CL: Risk factors for cutaneous squamous cell carcinoma recurrence, metastasis and disease-specific death: A systematic review and meta-analysis. JAMA Dermatol 152: 419-428, 2016.

10. Trodello C, Pepper JP, Wong M and Wysong A: Cisplatin and cetuximab treatment for metastatic cutaneous squamous cell carcinoma: A systematic review. Dermatol Surg 43: 40-49, 2017.

11. Wells JL, III and Shirai K: Systemic therapy for squamous cell carcinoma of the skin in organ transplant recipients. Am J Clin Oncol 35: 498-503, 2012.

12. Han C, Seebacher NA, Hornicek FJ, Kan Q and Duan Z: Regulation of microRNAs function by circular RNAs in human cancer. Oncotarget 8: 64622-64637, 2017.

13. Self-Fordham JB, Naqvi AR, Uttamani JR, Kulkarni V and Nares S: MicroRNA: Dynamic regulators of macrophage polarization and plasticity. Front Immunol 8: 1062, 2017.

14. Dang RY, Liu FL and Li Y: Circular RNA hsa_circ_0010729 regulates vascular endothelial cell proliferation and apoptosis by targeting the miR-186/HIF-1 $\alpha$ axis. Biochem Biophys Res Commun 490: 104-110, 2017.

15. Liu C, Wang J, Hu Y, Xie H, Liu M and Tang H: Upregulation of kazrin $\mathrm{F}$ by miR-186 suppresses apoptosis but promotes epithelial-mesenchymal transition to contribute to malignancy in human cervical cancer cells. Chin J Cancer Res 29: 45-56, 2017.

16. Zhang JJ, Wang DD, Du CX and Wang Y: Long noncoding RNA ANRIL promotes cervical cancer development by acting as a sponge of miR-186. Oncol Res: May 22, 2017 (Epub ahead of print).

17. He X, Ping J and Wen D: MicroRNA-186 regulates the invasion and metastasis of bladder cancer via vascular endothelial growth factor C. Exp Ther Med 14: 3253-3258, 2017.

18. Niu Q, Li X, Xia D, Jiang Y, Tian Z, Bian C, Zhang C, Liu P, Zhang F, Yang Y and Wang G: MicroRNA-186 affects the proliferation of tumor cells via yes-associated protein 1 in the occurrence and development of pancreatic cancer. Exp Ther Med 14: 2094-2100, 2017.

19. Wang Y, Chen F, Zhao M, Yang Z, Li J, Zhang S, Zhang W, Ye $\mathrm{L}$ and Zhang $\mathrm{X}$ : The long noncoding RNA HULC promotes liver cancer by increasing the expression of the HMGA2 oncogene via sequestration of the microRNA-186. J Biol Chem 292: 15395-15407, 2017

20. Shakeri R, Kheirollahi A and Davoodi J: Apaf-1: Regulation and function in cell death. Biochimie 135: 111-125, 2017.

21. De Zio D, Maiani E and Cecconi F: Apaf1 in embryonic development-shaping life by death and more. Int J Dev Biol 59: 33-39, 2015

22. Hickman ES and Helin K: The regulation of APAF1 expression during development and tumourigenesis. Apoptosis 7: 167-171, 2002.

23. Liu N, Sun YY, Zhang XW, Chen S, Wang Y, Zhang ZX, Song SW, Qiu GB and Fu WN: Oncogenic miR-23a in pancreatic ductal adenocarcinogenesis via inhibiting APAF1. Dig Dis Sci 60: 2000-2008, 2015.

24. Li J, Li Q, Huang H, Li Y, Li L, Hou W and You Z: Overexpression of miRNA-221 promotes cell proliferation by targeting the apoptotic protease activating factor-1 and indicates a poor prognosis in ovarian cancer. Int J Oncol: Mar 7, 2017 (Epub ahead of print). 
25. Livak KJ and Schmittgen TD: Analysis of relative gene expression data using real-time quantitative PCR and the 2(-Delta Delta C(T)) method. Methods 25: 402-408, 2001.

26. Yesantharao P, Wang W, Ioannidis NM, Demehri S Whittemore AS and Asgari MM: Cutaneous squamous cell cancer (cSCC) risk and the human leukocyte antigen (HLA) system. Hum Immunol 78: 327-335, 2017.

27. Karia PS, Morgan FC, Ruiz ES and Schmults CD: Clinical and incidental perineural invasion of cutaneous squamous cell carcinoma: A systematic review and pooled analysis of outcomes data. JAMA Dermatol 153: 781-788, 2017.

28. Grossi I, Salvi A, Abeni E, Marchina E and De Petro G: Biological function of MicroRNA193a-3p in health and disease. Int J Genomics 2017: 5913195, 2017.

29. Mulholland EJ, Dunne N and McCarthy HO: MicroRNA as therapeutic targets for chronic wound healing. Mol Ther Nucleic Acids 8: 46-55, 2017.

30. Wei F, Yang S and Wang S: MicroRNAs: A critical regulator under mechanical force. Histol Histopathol 33: 335-342, 2018.

31. Celano M, Rosignolo F, Maggisano V, Pecce V, Iannone M, Russo D and Bulotta S: MicroRNAs as biomarkers in thyroid carcinoma. Int J Genomics 2017: 6496570, 2017.

32. Shomali N, Mansoori B, Mohammadi A, Shirafkan N, Ghasabi M and Baradaran B: MiR-146a functions as a small silent player in gastric cancer. Biomed Pharmacother 96: 238-245, 2017.

33. Negoi I, Hostiuc S, Sartelli M, Negoi RI and Beuran M: MicroRNA-21 as a prognostic biomarker in patients with pancreatic cancer-A systematic review and meta-analysis. Am J Surg 214: 515-524, 2017.

34. Jang MH, Kim HJ, Gwak JM, Chung YR and Park SY: Prognostic value of microRNA-9 and microRNA-155 expression in triple-negative breast cancer. Hum Pathol 68: 69-78, 2017.

35. Neu J, Dziunycz PJ, Dzung A, Lefort K, Falke M, Denzler R, Freiberger SN, Iotzova-Weiss G, Kuzmanov A, Levesque MP, et al: miR-181a decelerates proliferation in cutaneous squamous cell carcinoma by targeting the proto-oncogene KRAS. PLoS One 12: e0185028, 2017.

36. Fleming JL, Gable DL, Samadzadeh-Tarighat S, Cheng L, Yu L, Gillespie JL and Toland AE: Differential expression of miR-1, a putative tumor suppressing microRNA, in cancer resistant and cancer susceptible mice. PeerJ 1: e68, 2013.

37. Lefort K, Brooks Y, Ostano P, Cario-André M, Calpini V, Guinea-Viniegra J, Albinger-Hegyi A, Hoetzenecker W, Kolfschoten I, Wagner EF, et al: A miR-34a-SIRT6 axis in the squamous cell differentiation network. EMBO J 32: 2248-2263, 2013.

38. Yamane K, Jinnin M, Etoh T, Kobayashi Y, Shimozono N, Fukushima S, Masuguchi S, Maruo K, Inoue Y, Ishihara T, et al: Down-regulation of miR-124/-214 in cutaneous squamous cell carcinoma mediates abnormal cell proliferation via the induction of ERK. J Mol Med (Berl) 91: 69-81, 2013.
39. Xu N, Zhang L, Meisgen F, Harada M, Heilborn J, Homey B, Grandér D, Ståhle M, Sonkoly E and Pivarcsi A: MicroRNA-125b down-regulates matrix metallopeptidase 13 and inhibits cutaneous squamous cell carcinoma cell proliferation, migration, and invasion. J Biol Chem 287: 29899-29908, 2012.

40. He J, Feng X, Hua J, Wei L, Lu Z, Wei W, Cai H, Wang B, Shi W, Ding N, et al: miR-300 regulates cellular radiosensitivity through targeting p53 and apaf1 in human lung cancer cells. Cell Cycle 16: 1943-1953, 2017.

41. Au Yeung CL, Co NN, Tsuruga T, Yeung TL, Kwan SY, Leung CS, Li Y, Lu ES, Kwan K, Wong KK, et al: Exosomal transfer of stroma-derived miR21 confers paclitaxel resistance in ovarian cancer cells through targeting APAF1. Nat Commun 7: 11150, 2016.

42. Song S, Seo HH, Lee SY, Lee CY, Lee J, Yoo KJ, Yoon C, Choi E, Hwang KC and Lee S: MicroRNA-17-mediated down-regulation of apoptotic protease activating factor 1 attenuates apoptosome formation and subsequent apoptosis of cardiomyocytes. Biochem Biophys Res Commun 465: 299-304, 2015.

43. Zang YS, Zhong YF, Fang Z, Li B and An J: MiR-155 inhibits the sensitivity of lung cancer cells to cisplatin via negative regulation of Apaf-1 expression. Cancer Gene Ther 19: 773-778, 2012.

44. Shang J, Yang F, Wang Y, Wang Y, Xue G, Mei Q, Wang F and Sun S: MicroRNA-23a antisense enhances 5-fluorouracil chemosensitivity through APAF-1/caspase- 9 apoptotic pathway in colorectal cancer cells. J Cell Biochem 115: 772-784, 2014.

45. Zou M, Lu N, Hu C, Liu W, Sun Y, Wang X, You Q, Gu C, Xi T and Guo Q: Beclin 1-mediated autophagy in hepatocellular carcinoma cells: Implication in anticancer efficiency of oroxylin A via inhibition of mTOR signaling. Cell Signal 24: 1722-1732, 2012.

46. Ravikumar B, Sarkar S, Davies JE, Futter M, Garcia-Arencibia M, Green-Thompson ZW, Jimenez-Sanchez M, Korolchuk VI, Lichtenberg M,Luo S, et al: Regulation of mammalian autophagy in physiology and pathophysiology. Physiol Rev 90: 1383-1435, 2010.

47. Klionsky DJ, Abeliovich H, Agostinis P, Agrawal DK, Aliev G, Askew DS, Baba M, Baehrecke EH, Bahr BA, Ballabio A, et al: Guidelines for the use and interpretation of assays for monitoring autophagy in higher eukaryotes. Autophagy 4: 151-175, 2008.

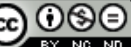

This work is licensed under a Creative Commons Attribution-NonCommercial-NoDerivatives 4.0 International (CC BY-NC-ND 4.0) License. 